funds of the Governments concerned, and from other sources.

The symposium was opened by Dr. T. Ziai (UnderSecretary, Ministry of Industries and Mines) on behalf of the Iranian Government, and by the Governor of Hamadan. Thereafter there were nineteen working sessions, including four general discussions, on a wide range of nuclear science topics. The proceedings were informal, and no record was kept; this no doubt contributed to the freedom and liveliness of discussion.

Perhaps the most valuable feature of the symposium was its impact on the nuclear science policies of the CENTO countries. To this end, many of the papers took the form of surveys in which the authors assessed what lines of work might be profitable in their particular field, and what they might involve in facilities and training. For example, Dr. D. I. Page, of the CENTO Institute, considered the application of isotopes to water-flow problems, with special reference to conditions in Turkey. He listed ten problems which had been proposed by the Hydraulics Research Laboratories in Ankara. Of these, four appeared impracticable for such reasons as the large amount of radioactivity involved; two others appeared of doubtful feasibility; and four others, estimation of suspended matter in flood water, detection of seepage points in irrigation channels, movement of underground water, and analysis of cement by radioactivation, were worth pursuing.

Another paper providing useful guidance to countries considering new programmes was that on mutation-breeding in agriculture, by Dr. H. J. Curtis of the Brookhaven National Laboratory. $\mathrm{He}$ emphasized the necessity of growing very large numbers of plants in such work; the fact that the variations produced by radiation can also be produced by more conventional means; the need for a lengthy programme of orthodox plant-breeding before a commercially valuable variety can be derived from a radiation-produced mutant; and the meagre results to date in terms of new commercial varieties. Nevertheless, the fundamental aspects of the work fully justify continued effort.
Further papers in the same category were those on prospecting for radioactive minerals, on running a fall-out laboratory, on the use of carbon-14 in biochemistry, and on establishing a medical radioisotope clinic. There were also general discussions on the potentialities of radioisotope applications in the CENTO region, on their applications in the oil industry, and on atomic energy and public health.

Iran, as the host country, naturally sent the strongest delegation to the symposium, and this gave an opportunity for direct discussion of her nuclear science programme. Prof. A. A. Azad, who is in charge of the Tehran University Nuclear Centre, gave a general account of the programme, which includes a 5-MW. swimming-pool type reactor to be operating in 1962 ; and Dr. A. A. Sheibani described the Iranian radioactive prospecting project. The discussion which followed ranged over such fundamental issues as the possible uses of a large research reactor, and the value to the region of some of the larger nuclear instruments. The interest aroused was such that both the Pakistani and Turkish delegations expressed a desire for similar international discussions in their own countries.

Other topics at the symposium included reactor instrumentation, waste disposal and recent applications of radioisotopes in medicine, besides various research reports on nuclear physics and on applications of radioisotopes in botany and entomology.

The ohoice of Hamadan, a quiet, historic town, as the venue of the symposium, rather than Tehran, was something of a novelty to the Iranians, but was much appreciated by all the delegates on account of the relaxed atmosphere and opportunities for informal contacts that it provided. The local authorities contributed to this by their welcome and by their generosity in providing a meeting place, excursions and other amenities. As a final charming gift they gave each delegate a framed picture of a soientist of former days, Avicenna, whose home town was Hamadan.

H. A. C. MoKay

\title{
CONVECTION IN METEOROLOGY
}

T THE subject of "Convection" was chosen as the topic of the symposium for the first day of the Royal Meteorological Society's summer meeting held in the Electrical Engineering Department, Queen's College, Dundee, on June 30. This was the first meeting of the Society ever to be held in Dundee, and was to be followed on the next day by a symposium on "Agricultural Meteorology" (see Nature, $187,995 ; 1960)$. The president of the Society, Dr. J. M. Stagg, took the chair.

The opening speaker was Dr. F. H. Ludlam of the Imperial College of Science and Technology who reviewed the subject of convection in the atmosphere. This is a phenomenon which ranges in scale from the currents associated with fair-weather cumulus to those in the large thunderstorms which result in extensive flooding. Whereas the dynamics of the smaller currents are broadly understood as circulations associated with rising bubbles or columns of warm air, the dynamics of thunderstorms, or for that matter, the precise physical processes involved, are not so well understood. The Bénard convection cell pattern, for which a theory exists, does not seem to occur frequently in the atmosphere, although recent photographic evidence from an American weather research rocket shows a regular pattern of 'groups' of cumulus. The most satisfactory method of forecasting the extent of cumulus development still seems to be that based on the old 'parcel' theory, where the air is assumed to form into bubbles or 'parcels', which break away from the surface and rise adiabatically through the environment until a layer sufficiently stable to prevent further penetration is reached. This method entirely neglects any modification of the environment, such as subsidence warming, and leads to little real understanding of the dynamies of the process.

The difference between a large cumulus extending to, say, $15,000 \mathrm{ft}$., and a cumulonimbus, with its associated characteristics of hail and lightning, seems 
to be more than an enlargement of scale of the same process. A completely new physical factor seems to be involved resulting in up-currents which may be as large as 80 m.p.h. and horizontal currents of up to 60 m.p.h. Radar observations made by workers from the Imperial College of Science and Technology and the Meteorological Office have shown air to move into the base of such a storm at 60 m.p.h., and maintain this speed while passing vertically up through the storm, flowing horizontally out of the top at a height of 7 or 8 miles. The kinetic energy of such a system extending over a horizontal region of about 20 square miles is $100-1,000$ times that of a typical large cumulus producing a moderate rain shower. The exceptional rate of growth to a thunderstorm of this size from the typical large cumulus usually occurs after rain has started falling. A physical feature of these thunderstorms which indicates the great energy of the up-draught is the exceptional size of hailstorms produced, which may be as large as golf balls. The latent heat of fusion released during their growth may be an additional source of energy, acting as a kind of booster to convection originated by surface heating.

Many of the vigorous thunderstorms affecting southern England have their origins over northern France and are propagated, rather than simply carried, in the upper-wind system. A strong-wind shear is always associated with these storms and they exhibit a well-defined anvil of cirrus cloud.
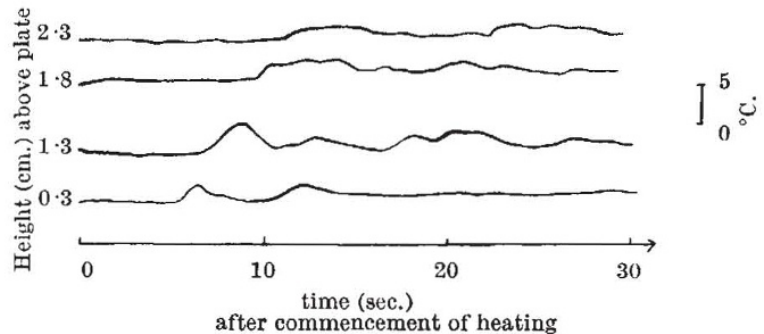

Jig. 1. Temperature fluctuations observed above a heat source in water. Rate of heating of plate $=40 \mathrm{~W}$.

Dr. Ludlam was followed by Mr. C. Dixon of Queen's College, Dundee, who described an experiment he had performed on the initiation of convection currents in water. A semi-circular copper plate $5 \mathrm{~cm}$. in diameter with an embedded electrical heating element was placed on the bottom of a tank of water with the straight edge adjacent to the 'Perspex' front of the tank. Thermocouples were set on to this face at intervals of $\frac{1}{2} \mathrm{~cm}$. above the heater and temperature variations at these levels rocorded on a Cambridge 6-channel oscillograph. A tracing of a typical rocording is shown in Fig. I. A period of about 10 sec. (depending on the rate of heating) elapsed before any temperature fluctuation was observed, and then an initial pulse travelled past the thermocouples in succession, followed by further pulses at fairly regular intervals of $2-3$ sec. On switching the heater off, the pulses died away after a few seconds. It is hoped eventually to photograph tracers to determino the

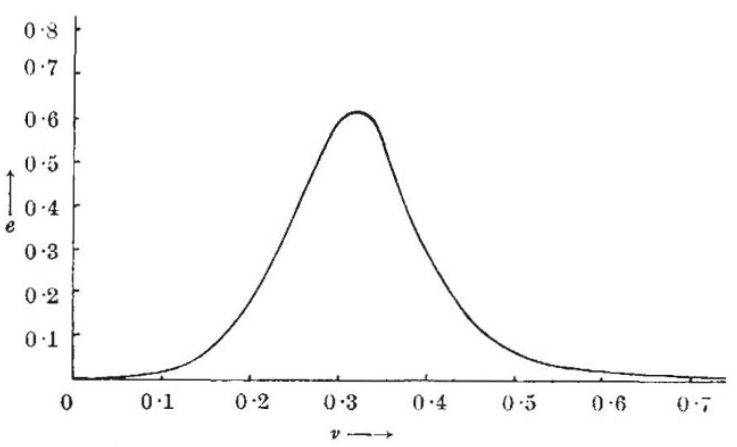

liig. 2. Absorption of energy by gravity waves at an inversion.

$$
e=E / r^{4} g \Delta \rho, v^{2}=\frac{1}{2 \pi \pi^{2}} \cdot \frac{g r \Delta \rho}{w \rho}
$$

$Z_{i}=$ energy absorbed by waves, $\rho=$ density of lower laye,

$\Delta \rho=$ density defieit of the upper layer, $r$ radius of bubble

$$
w=\text { velocity of rise }
$$

velocity distribution in these currents and associate this with the termperature variations.

The third contributor to the symposium was $\mathrm{Mr}$. F. W. G. Warren of the University of Sheffield, who explained a mathematical theory he had developed to determine what proportion of the kinetic energy of ascent of a thermal bubble or column was used in the production of gravity waves at an interface when the bubble or column penetrated a more stable layer. His results showed that such wave production was a maximum when the temperature of the rising column was about midway between those of the upper and lower layers near the interface, that is, such that the bubble was buoyant with respect to the lower layer, but not with respect to the upper. The dependence of the gravity wave-energy on the velocity of the bubble and its size is shown in Fig. 2.

The closing speaker was Dr. R. P. Pearce of Queen's College, Dundee, who explained a theory he had worked out for the development of sea-breezes and which also, with only slight modification, applied to the development of convection currents. The fundamental problem in both these cases is to solve the equations of heating and motion to give the velocity and temperature distributions at any time resulting from a given rate of heat-input. In the case of the sea-brceze this means predicting the time of onset of an onshore wind, and its strength, at any point inland from the coast, given the rate of heating well inland. In the convection problem it means being able to calculate the rates of growth of currents of various sizes from

\section{$0.2 \mathrm{hr}$}
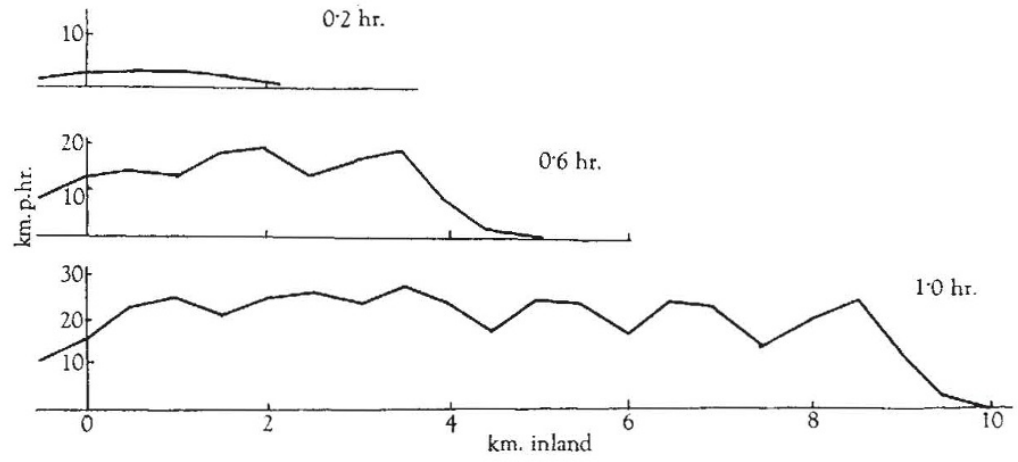

Fig. 3. Sea-breeze development. Surface velocity in km. per hr. Rate of heating $3^{\circ} \mathrm{C}$. per hr. beyond $2 \mathrm{~km}$. inland, decreasing towards the coast. Atmosphere initially static 


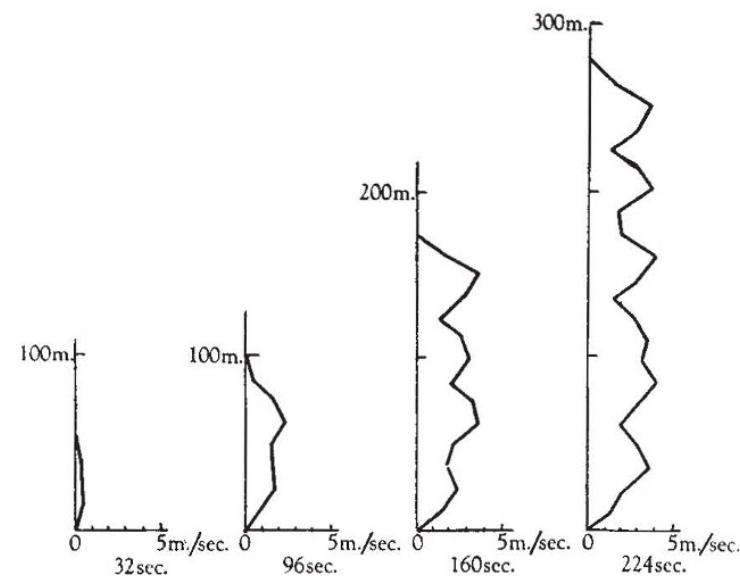

Fig. 4. Development of a thermal. Velocity in m. per sec. Atmoslihere assumed initially static with dry adiabatic lapse-rate. Rate of heating approximately $1^{\circ}$ C. per 3 min. up to $25 \mathrm{~m}$. $1^{\circ} \mathrm{C}$. per 6 min. at $37.5 \mathrm{~m}$, and zero above $50 \mathrm{~m}$.

the known rate of heating that produces them. In both problems the velocity and temperature distributions can be taken as two-dimensional, assuming no variations parallel to a long straight coastline in the case of the sea-breeze, and symmetry about a vertical axis in the case of a convection current. Nevertheless, tho mathematical problem is still very complex, involving frequent integrations of Poisson's equation in two dimensions, a time-consuming process even for an electronic computer. A further simplification was therefore made assuming the form of the vertical distributions of velocity and temperature for the sea-breeze, and the radial distributions for the convection current. These assumptions are not unreasonable when the vorticity distribution is elongated, in this case horizontally for the sea-breeze and vertically for the convection current. The result, after introducing boundary conditions and integrating the equations to include the assumed distributions, is to eliminate one of the space variables, leading to a single partial differential equation to be solved for the surface (or axial) velocity $u$ as a function of distance from the coast (or ground) $x$ and the time $t$. This equation is of the form:

$$
\frac{\partial^{2} u}{\partial t^{2}}+a \frac{\partial^{2}\left(u^{2}\right)}{\partial x \partial t}+b \frac{\partial^{2}\left(u^{3}\right)}{\partial x^{2}}=\mathbf{F}(x, t)
$$

Here $a$ and $b$ are numerical constants with values depending on the assumed profiles of velocity and temperature. $\mathrm{F}(x, t)$ is the horizontal gradient of the heating-rate in the case of the sea-breeze and can be taken as zero everywhere except near the coast. In the case of the convection current, it is the actual heating rate, and this can be taken as zero everywhere except near the ground. The equation is nonlinear since no linearizing assumptions are made in the analysis. Some results of the numerical integration, using the Deuce computer at the University of Glasgow, are shown in Figs. 3 and 4.

The initial development of the sea-breeze near the coast and its subsequent penetration inland are features of the result illustrated by Fig. 3, and the analogous generation of the convection current at the surface and its penetration upwards is illustrated in Fig. 4. In both cases the onset at a point away from the origin is fairly sudden and 'frontal' in nature. Another interesting feature is the series of pulses behind the initial one. There is observational evidence for this occurring after the onset of a sea-breeze, and Mr. Dixon's observations described earlier show this property for a convection current in water. These fluctuations may, however, have been introduced into the computation as a result of truncation errors in the finite-difference approximations used in the integration of the equation. Further computations with different heating-rates show that smaller currents develop more rapidly than larger oncs, as one observes on a typical convection day when the larger clouds usually develop during the late morning or afternoon.

The symposium ended with a general discussion. Dr. Ludlam's dynamical picture of a thunderstorm was discussed at some length and it became obvious that here was a useful field of study for the dynamical meteorologist, for no mathematical theory which can account for even the broadest features of these storms at present exists.

R. P. Pearce

\section{SAFETY OF FACTORY WORKERS}

T THE annual report of the Chief Inspector of Factories for 1959 reports a further decline in the number of fatal accidents, from 665 in 1958 to 598 in 1959 , the lowest figures recorded this century*. While this figure continues the consistent downward trend in fatalities from the 828 in 1951 , the downward trend in total accidents of the previous three years was checked, and the number of reported accidents rose from 167,697 in 1958 to 174,071 , in spite of increased activities in the field of accident prevention, although it may be partly explained by the increase in the number of people employed and hours worked. The Chief Inspector, however, finds the increase in the number of accidents to young

* Ministry of Labour and National Service. Annual Report of the Chicf Inspector of Factories for the year 1959. Pp. 128. (Cmnd. 1107.) (London: H.M. Stationery Office.) $7 s$. net. persons disturbing, and one of two chapters in the report dealing with subjects of interest without being necessarily restricted to the events of the year deals with the prevention of accidents to young persons. This has been discussed in Nature of November 5 , p. 460 ; the other special chapter deals with designing machinery for safe operation. Besides directing attention to some of the more important safety principles, which, it is suggested, machine manufacturers should bear in mind, it urges that every opportunity should be taken to bring such eonsiderations before the professional, research and teaching authorities concerned, and that industry as the user should insist on getting premises, plant and equipment with safety 'built in' by the suppliers.

As a result of a considerable number of changes made in the analysis and classification of information 